\title{
A AÇÃO DO IMPERIALISMO NA REPRODUÇÃO DO CORPORATIVISMO NOS SINDICATOS DOS TRABALHADORES EM EDUCAÇÃO
}

\author{
Marilsa Miranda de Souza \\ Tatiane Furtado Ricarte \\ Márcio Marinho Martins
}

\begin{abstract}
RESUMO
Este artigo é resultado do desenvolvimento da pesquisa "O corporativismo sindical como elemento de sustentação das relações semicoloniais e semifeudais na educação brasileira" que teve como objetivo analisar as relações estabelecidas entre dois sindicatos rondonienses, o sindicato dos Trabalhadores em Educação do Estado de Rondônia SINTERO e o Sindicato dos Servidores Públicos da Zona da Mata - SINSEZMAT com seus filiados e com o Estado, o processo de organização sindical no Brasil e sua submissão às políticas educacionais formuladas pelo imperialismo para suas semicolônias identificando os aspectos do corporativismo e suas consequências no processo de organização dos trabalhadores em Educação e no desenvolvimento da luta de classes na atualidade. Utilizamos o método do materialismo histórico-dialético por meio do qual buscamos interpretar a realidade a partir de suas categorias básicas que permitiu compreender o sindicato como aparelho ideológico do Estado a serviço da grande burguesia e do imperialismo na atualidade. A pesquisa demonstrou a precarização do trabalho e a desvalorização dos trabalhadores em Educação em Rondônia, o descrédito dos entrevistados em relação aos sindicatos e a necessidade construir sindicatos classistas que contribuam para o avanço da luta revolucionária.

Palavras-chave: Imperialismo; Capitalismo Burocrático; Corporativismo sindical.
\end{abstract}

\section{THE IMPERIALISM ACTION IN PLAY IN THE CORPORATISM UNIONS OF WORKERS IN EDUCATION}

\begin{abstract}
This article is the result of research development "The union corporatism as support element of semi-colonial and semi-feudal relations in Brazilian education" that aimed to analyze the relations established between two Rondônia unions, the Union of Education Workers of the State of Rondônia - SINTERO and the Union of Civil Servants of Forest Zone - SINSEZMAT with its members and with the state, the union process in Brazil and its submission to the educational policies formulated by imperialism for their semicolonies identifying aspects of corporatism and its consequences in the process of organization of workers in education and the development of the class struggle today. We use the method of historical and dialectical materialism through which we seek to interpret reality from their basic categories that allowed to understand the union as an ideological apparatus of the state in the service of the big bourgeoisie and imperialism today. The research demonstrated the precariousness of work and the devaluation of workers in Education in Rondônia, the discrediting of the respondents in relation to the trade unions and the need to build classist unions that contribute to the advancement of the revolutionary struggle.
\end{abstract}

Keywords: Imperialism; Bureaucratic capitalism; Union corporatism 


\section{INTRODUÇÃO}

O presente artigo é parte do desenvolvimento da pesquisa "o corporativismo sindical como elemento de sustentação das relações semicoloniais e semifeudais na educação brasileira", que teve como objetivo analisar as relações estabelecidas entre o Sindicato dos Trabalhadores em Educação do Estado de Rondônia - SINTERO e do Sindicato dos servidores públicos da Zona da Mata - SINSEZMAT com seus filiados e com o Estado, o processo de organização sindical no Brasil e sua submissão às políticas educacionais formuladas pelo imperialismo para suas semicolônias identificando os aspectos do corporativismo e suas consequências no processo de luta dos trabalhadores em Educação.

Utilizamos o método do materialismo histórico-dialético, entendido como um instrumento de compreensão da realidade enquanto práxis e de interpretação que possibilite uma intervenção transformadora. $\mathrm{Na}$ análise e interpretação dos dados buscamos interpretar a realidade objetiva e subjetiva em termos das categorias totalidade, contradição, ideologia e práxis, estudando as relações sociais e econômicas que determinam a educação e a produção das ações concretas dos sujeitos históricos que dela fazem parte. Também aplicamos duas categorias históricas fundamentais que nos ajudam a elucidar as relações de dominação existentes na esfera socioeconômica, política e cultural e que incidem sobre as políticas educacionais e as relações de poder estabelecidas no ambiente escolar e nas relações sociais de produção da sociedade. São elas: imperialismo $e$ capitalismo burocrático. A aplicação destas categorias permite compreender o sindicato como aparelho ideológico do Estado a serviço da grande burguesia e do imperialismo na atualidade.

Para compreendermos o conceito de imperialismo, utilizamos como referência a obra de Lênin Imperialismo: etapa superior do capitalismo (LÊNIN, 1979) e o conceito de Capitalismo Burocrático as contribuições de Guzman (1974), Martín Martín (2007), Mariátegui (2008), Campos (2011) e Souza (2014).

O século XX é assinalado por Lênin como o ponto de virada do velho capitalismo para o novo, da dominação do capital em geral para a dominação do capital financeiro. Essa fase é marcada pela forte presença dos bancos que, aumentando o número de operações, gera o monopólio (LÊNIN, 1979, p. 12). Com o surgimento do monopólio, ocorreu a divisão do mundo entre os países imperialistas, que disputavam territórios ainda não ocupados para que pudessem ter mais matérias-primas que garantissem sua produção e lucro. Assim, a concentração de capitais chega num ponto tão elevado que se acentuam os saques nas colônias e semicolônias (LÊNIN, 1979, p. 35).

A dominação imperialista em nosso país nas últimas décadas apresenta características bem particulares, dado seu desenvolvimento, mas a análise leninista é a única capaz de explicá-las na atualidade, já que os monopólios, as exportações de capitais e o capital financeiro - essência dessa fase superior do capitalismo - continuam a todo vapor, fortalecendo os interesses de seus grandes blocos econômicos. Esses interesses se manifestam por meio da ação de seus organismos multilaterais, da desregulamentação do Estado, dos projetos de privatização, etc., para garantir os ajustes estruturais necessários à sobrevivência do imperialismo.

Para compreender a ação do imperialismo em nosso país utilizaremos o conceito de capitalismo burocrático, que foi criado por Mao Tsetung (2008) na análise do capitalismo 
chinês e desenvolvido por Guzmán (1974). Guzmán aprofundando o conceito de capitalismo burocrático, o define como "o capitalismo que o imperialismo impulsiona num país atrasado; o tipo de capitalismo, a forma especial de capitalismo, que impõe um país imperialista a um país atrasado, seja semifeudal, semicolonial” (GUZMÁN, 1974, p. 1).

O conceito de capitalismo burocrático se aplica à análise de todos os países que não fizeram a revolução burguesa e mantêm o problema agrário. Para Souza (2014), o Brasil é um país de capitalismo burocrático, pois embora tenha se desenvolvido, o capitalismo no Brasil, não realizou uma revolução democrático-burguesa e nunca democratizou a propriedade da terra. Ao contrário, somente acentuou o monopólio da terra e a manutenção de relações semifeudais que ainda hoje encontramos no campo e na cidade. Segundo Guzman (2014), O capitalismo burocrático tem duas colunas: semicolonialismo e semifeudalidade (grande propriedade, semisservidão, gamonalismo ou coronelismo), que são interligadas e indissolúveis. Com base nessa afirmativa, Souza (2014, p.81) afirma que o Brasil é um país de capitalismo burocrático e explica as razões:

Em resumo, desde quando o Brasil era colônia de Portugal, convivemos com dois grandes problemas: o problema da concentração da terra e o problema nacional, como na maioria dos países da América Latina. O problema da terra porque mantivemos uma das maiores concentrações de terra do mundo e o modelo agroexportador. Nossa agricultura, ao longo dessa história, tem servido à exportação de alimentos e de matériasprimas para enriquecer as potências imperialistas, enquanto o povo brasileiro vive imerso na miséria e na exploração. E o problema nacional, porque nunca tivemos autonomia para dirigir o Estado além da manutenção e reprodução de uma mentalidade colonizada e enganada com uma falsa liberdade sujeitando-nos ao extremo a todas as formas de dominação. (SOUZA, 2014, p. 81, Grifo da autora).

Sendo assim, buscaremos no conceito de Imperialismo e Capitalismo burocrático os aportes teóricos básicos para compreender historicamente o desenvolvimento dos sindicatos e suas ações na atualidade, especialmente em relação às lutas dos trabalhadores em educação.

\section{BREVE HISTÓRICO DO SINDICALISMO E A LUTA DE CLASSES NO BRASIL ATUAL}

O Brasil desenvolveu-se com um país de capitalismo burocrático, semifeudal e semicolonial. No século XIX, período em que se vivenciou a decadência do trabalho escravo no Brasil, onde a economia do país baseava-se na produção da monocultura do café para exportação, que se tem início as primeiras indústrias no Brasil. Com as indústrias, inicia-se a constituição da classe operária brasileira e suas primeiras organizações classistas.

O nascente proletariado brasileiro dá seus primeiros passos e registra-se em 1858 a primeira greve operária no Brasil: a dos tipógrafos do Rio de Janeiro, que lutavam por melhores condições de salários e contra a exploração dos patrões. A greve dirigida pela Associação Tipográfica Fluminense, criada em 1853, reuniu trabalhadores de pelo menos 03 jornais do Rio de Janeiro. Segundo Batalha (1999), no período compreendido entre 1835 e 1899 foram criadas no Rio de Janeiro, 46 sociedades de trabalhadores, de mais variadas formas de organização, como cooperativas, educacionais, culturais e de ajuda mútua (BATALHA, 1999, p. 57). 
Segundo Marcelo Badaró Mattos (2009) já em 1876, uma greve de trabalhadores aconteceu em Santos "paralisando as padarias da cidade, na qual os trabalhadores escravizados fugiram do local e falsificaram cartas de alforrias para conseguir outro trabalho posteriormente". (MATTOS, 2009, p.13). Esses trabalhadores após a abolição da escravatura criaram a Sociedade Cosmopolita Protetora dos Empregados em Padaria, que tinha como finalidade lutar em defesa de seus direitos, como um sindicato, porém, não era registrado.

Segundo Mattos (2009, p. 30), "trabalhadores escravizados e livres partilharam formas de organização e de luta, construindo propostas e expectativas comuns, que acabariam tendo uma importância central para momentos posteriores do processo de formação da classe". Essa junção entre trabalhadores assalariados e escravos livres contribuiu para a identidade da classe operária brasileira. No fim do império, com medo de ver aquele "bando de ex-escravos" sem trabalhar, a câmara dos deputados, poucos dias após a promulgação da Lei Áurea, aprovou a Lei de Repressão à Ociosidade, onde eram presos todos os que não trabalhassem e, ao mesmo tempo, era uma forma de garantir trabalhadores a baixo custo para as fábricas (MATTOS, 2009, p.34).

No final do século XIX e início do século XX, mais precisamente entre 1897 e 1915, foram fundadas diversas organizações operárias, "ligas" e "uniões", de caráter classista e de ideologia anarquista e socialista, estimadas em cerca de 200 organizações de categorias de profissionais que se espalharam do Amazonas ao Rio Grande do Sul. (FERREIRA, 1978, p. 14).

Em São Paulo, que na virada do século XIX para o Século XX torna-se o principal centro industrial brasileiro, por volta de 1901, concentra aproximadamente 50.000 operários, sendo a maioria compostas de italianos e, consequentemente, influenciados pelas ideias anarquistas, que em momento de crise, falências de empresas e desemprego, tiveram grande influência entre o operariado (PENTEADO, 1962, p.139).

O avanço da organização proletária no Brasil possibilitou a realização do I e II Congresso Socialista Brasileiro (1892 e 1902, respectivamente) e que marcam, mesmo de forma tímida a influência das ideais de Marx e Engels. Em 1902, das 37 associações de trabalhadores que participaram do Congresso, 25 eram paulistas. A organização operária e a força da mobilização foram demonstradas em diversas greves, como as de Santos, em 1905 e 1908; e em São Paulo em 1912, que envolveu 10.000 trabalhadores e duraram 30 dias.

A organização dos operários em âmbito nacional se deu no primeiro Congresso Operário Brasileiro (1906) que, contando com a participação de 43 delegados, fundou a Confederação Operária Brasileira (COB), cuja luta era voltada para diversas lutas reivindicativas e de solidariedade às lutas operárias de outros países. Ao passo que cresce a organização operária, cresce também a repressão estatal que se municia de uma legislação mais repressiva, sobretudo contra operários estrangeiros, como o decreto $n^{\circ} 1.641$, de 7 de janeiro de 1907, mais conhecida como Lei Adolfo Gordo ${ }^{4}$, que previa expulsar em nome da "segurança nacional" e da "tranquilidade pública", lideranças operárias imigrantes.

Além de intensa repressão legal e violenta, o Estado recorreu à influência da igreja para persuadir os operários e afastá-los do perigo "ateu comunista". Sob a influência da Encíclica Rerum Novarum, do papa Leão XIII, a igreja católica também buscou intervir nas fábricas e no meio operário, como uma forma de criar certa harmonia entre capital e trabalho. Posteriormente, por meio da Ação Católica, deu origem a diversos movimentos no interior da sociedade, como a Juventude Estudantil Católica (JEC), a Juventude 
Universitária Católica (JUC), a Juventude Agrária Católica (JAC) e a Juventude Operária Católica (JOC). Na atualidade a JOC e a Pastoral Operária têm trabalho em grandes centros operários e seus militantes, em sua maioria, apoiam o Partido dos Trabalhadores (PT). Leão XIII, através da Encíclica Renum Novarum tratou de atacar de forma implacável o materialismo histórico-dialético e a formulação marxista da "luta de classes" e da luta contra a propriedade privada:

Mas, e isso parece ainda mais grave, o remédio proposto está em oposição flagrante com a justiça, porque a propriedade particular $e$ pessoal é, para o homem, de direito natural. (...) Primeiramente, no homem reside, em sua perfeição, toda virtude da natureza sensitiva, e desde logo lhe pertence, não menos que a esta, gozar dos objetos físicos e corpóreos. (LEÃO XIII, 2015, p. 3, grifo e negrito nosso).

Por tudo o que Nós acabamos de dizer, se compreende que a teoria socialista da propriedade coletiva deve absolutamente repudiar-se como prejudicial àqueles mesmos a que se quer socorrer, contrária aos direitos naturais dos indivíduos, como desnaturando as funções do Estado, e perturbando a tranquilidade pública. Fique, pois, bem assente que 은 princípio fundamental a estabelecer para aqueles que querem sinceramente o bem do povo, é a inviolabilidade da propriedade particular. (LEÃO XIII, 2015, p. 5, grifo e negrito nosso).

O erro capital na questão presente é crer que as duas classes são inimigas natas uma da outra, como se a natureza tivesse armado os ricos e os pobres para se combaterem mutuamente num duelo obstinado. (LEÃO XIII, 2015, p. 6, grifo e negrito nosso).

O primeiro princípio a pôr em evidência é que o homem deve aceitar com paciência a sua condicão: é impossível que na sociedade civil todos sejam elevados ao mesmo nível. É, sem dúvida, isto o que desejam os Socialistas; mas contra a natureza todos os esforços são vãos. Foi ela, realmente, que estabeleceu entre os homens diferenças tão multíplices como profundas; diferenças de inteligência, de talento, de habilidade, de saúde, de força; diferenças necessárias, de onde nasce espontaneamente a desigualdade das condições. Esta desigualdade, por outro lado, reverte em proveito de todos, tanto da sociedade como dos indivíduos; porque a vida social requer um organismo muito variado e funções muito diversas, e o que leva precisamente os homens a partilharem estas funções é, principalmente, a diferença das suas respectivas condições. (LEÃO XIII, 2015, p. 20, grifo e negrito nosso).

Associada à intensa repressão e ação da igreja católica, a postura anarquista contribuiu para o enfraquecimento do movimento operário. Suas reivindicações exclusivamente econômicas, a negação da luta política e sua postura contra a organização de um partido político operário oportunizaram ao surgimento do Partido Comunista do Brasil - PCB, fundado em 1922 (MATTOS, 2009, p. 50), apenas cinco anos após a primeira revolução socialista vitoriosa, a revolução bolchevique de 1917, na Rússia. Já em 1925, A Classe Operária, órgão informativo do PCB, teve sua primeira tiragem com 5 mil exemplares. O PCB fomentou e contribuiu para a fundação, em 1929, da CGT - Central Geral dos Trabalhadores.

O período republicano é marcado pela política do café-com-leite, destacando-se pela prática do coronelismo pelos latifundiários. A maioria da população não votava porque não estavam dentro dos padrões exigidos pelos senhores. O nível de desigualdade era visível e ainda o é em nosso país. Tivemos índices de crescimento elevado, porém, um 
nível de concentração de riquezas ainda maior, alavancando assim a superexploração do trabalhador e camuflando suas as péssimas condições de vida.

Surgem os sindicatos "amarelos" que defendiam a aliança entre Estado e trabalhador para que os objetivos da classe explorada fossem alcançados. Afirmavam que gostavam da praticidade e não da utopia defendida pelos anarquistas e que somente com essa junção poderiam ter sucesso em suas lutas sindicais (MATTOS, 2009, p.52).

Com Getúlio Vargas intensifica-se o discurso de harmonia entre os trabalhadores e os capitalistas. Vargas marcou sua política pelo incentivo ao nacionalismo e ao patriotismo, criando várias leis trabalhistas e, dentre elas, a legislação sindical que instituiu o monopólio de representação, isto é, um único sindicato por categoria e região, na qual estaria divido entre local, regional e nacional, para que pudesse controlar o trabalho dos mesmos a partir da criação do MTIC (Ministério do Trabalho Indústria e Comércio) que tinha o poder de fiscalizá-los e intervir sempre que necessário nas suas direções de representatividade (MATTOS, 2009).

Seu objetivo era fazer com que todos os sindicatos autônomos se tornassem oficiais para serem controlados pelo Estado, todavia, muitos sindicatos não queriam esse atrelamento, exceto os sindicatos amarelos que defendiam a relação entre governo e sindicalismo. O MTIC criou estratégias para que esses sindicatos aderissem a essa política. Assim, só poderiam usufruir dos benefícios da legislação trabalhista somente os sindicatos oficiais, colocando assim os autônomos de "manga curta" (MATTOS, 2009).

A constituição de 1934 confirmou o modelo de sindicato oficial no país, sendo um período marcado por várias greves e a exigência de um sindicato desvinculado do controle do Estado e de uma democracia que não fosse apenas representativa.

No Levante comunista de 1935 "o governo decretou uma lei de segurança nacional que instalou o Estado de exceção, ao criar os mecanismos e tribunais especiais para os presos políticos" (MATTOS, p. 69). Nesse ato, vários líderes sindicais foram presos, tiveram seus direitos cassados, alguns foram presos ou afastados do cargo de presidente. Os governantes tinham medo de ser instalado o comunismo no Brasil e por esse motivo reprimiram as lideranças sindicais vinculadas ao PCB. Em 1935 alguns dirigentes do MTIC assumiram a presidência dos sindicatos e por serem atreladas ao governo, não houve mobilizações e o sindicato brasileiro se ausentou das lutas.

Mas, as lutas dos trabalhadores que acreditavam em um sindicato combativo, não pararam. Quando Vargas percebeu que seriam tempos de lutas incessantes, mudou rapidamente sua retórica, dizendo que em todo o seu mandato a figura do trabalhador seria muito bem valorizada, fazendo-se de "pai dos pobres" para se reeleger novamente. Com o crescente desgaste de seu governo e num contexto de derrota de regimes fascistas, Vargas tomou várias medidas acenando para um período de "redemocratização" depois de uma terrível ditadura, como o reconhecimento legal do PCB e de outros partidos (1943), a libertação de presos políticos, etc.. Em relação à organização sindical, manteve a estrutura de atrelamento e submissão dos sindicatos ao Estado.

O "aceno" de Vargas para uma "redemocratização", sua posição em relação ao apoio dado aos aliados na segunda guerra mundial (que incluía a URSS) contribuiu para que no interior do PCB se travassem intensas lutas em torno de posições sobre a caracterização da burguesia brasileira. Desde 1941, o PCB, de forma clandestina, tentava se organizar com a Comissão Nacional de Organização Provisória - CNOP, que escaparam do cerco da repressão. Muitos dirigentes do PCB foram tomados pela falsa ideia 
de que, com a derrota do fascismo abrira-se a possibilidade para uma transição pacífica no mundo, caindo nas ilusões constitucionais e lançando uma palavra de ordem "Constituinte com Vargas". Alguns dirigentes do PCB, como afirmou Jacob Gorender", via em Vargas a representação de uma "burguesia nacional" que "queria o desenvolvimento e a independência do País" e que se contrapunha à outra fração da burguesia que era "servil ao imperialismo". Foi uma posição errada que levou o PCB ao mais profundo gueto do revisionismo e do oportunismo eleitoral, negando os princípios do marxismo e a luta revolucionária.

O governo de Dutra não foi muito diferente. Continuou vigiando os militantes e organizações sindicais e intensificando o arrocho salarial. A vida se tornou mais dura de viver, pois os trabalhadores ganhavam pouco e pagavam caro para sobreviver em meio às favelas e os subúrbios. Os membros do PCB foram perseguidos, os mandatos de seus parlamentares cassados e novamente o partido voltou para a clandestinidade.

No governo de Juscelino Kubistchek a prioridade foi o crescimento da indústria, que era o foco do slogan "50 anos em 5". O financiamento para o conjunto de ações contidas no Plano de Metas de JK viria de empréstimos contraídos no exterior e a abertura da economia brasileira para grandes empresas multinacionais, entre as quais as grandes montadoras.

No período em que antecede o golpe militar de 1964, o Brasil mantém-se sob a influência cada vez mais crescente do imperialismo norte-americano. Ao mesmo tempo, há uma crescente adesão às ideias socialistas no mundo, com revoluções ocorrendo na China (1949), Cuba (1959) e lutas de libertação nacional dirigidas pelos comunistas (Vietnã, Moçambique, Angola, etc.). No Brasil, há um crescente processo de organização dos trabalhadores nas cidades e também no campo com a fundação das Ligas Camponesas.

No governo Jango, em virtude da crescente organização e pressão dos trabalhadores, houve uma abertura dos espaços políticos para as propostas dos sindicatos, porém, sem deixar em nenhum momento de tentar controlar todas as mobilizações dos trabalhadores, já que este era tido como herdeiro político do populismo de Getúlio Vargas. Com essa abertura política muitos sindicatos apoiaram Jango acreditando que o exército e as forças armadas brasileiras iria impedir o golpe civil-militar.

O golpe de 1964 suprimiu as liberdades individuais, partidos foram cassados, decretou-se o fim das greves e a Doutrina de Segurança Nacional, foi transformada em Lei para perseguir os "inimigos internos" e o "perigo comunista". Em relação à luta sindical, houve intervenções em 433 sindicatos, seus líderes foram presos ou estavam com inquéritos policiais e os poucos os dirigentes combativos que restaram tiveram que partir para a clandestinidade ou ir para outro país. Nesse período do golpe até 1967 o sindicalismo brasileiro viveu sobre mordaças, os trabalhadores não tinham direito a voz e nem vez e o que permaneceu foi o "não direito" do trabalhador. Em 1967 o Ministério do Trabalho fez eleições para os dirigentes sindicais, controlando-os.

A ditadura na década de 1970 entra em colapso, favorecendo a volta dos exilados e das reorganizações partidárias com uma abertura política lenta e gradual. No final da década de 1970 inicia-se uma movimentação política que culminou com a fundação do PT (Partido dos Trabalhadores) e da CUT (Central Única dos Trabalhadores). Neste cenário, fabricou-se a liderança de Luiz Inácio, o Lula. Contudo, muitos comunistas alertavam para o seu papel conciliador de classes, características de uma liderança que seguia os ditames da Doutrina Social da Igreja Católica e do Sindicalismo amarelo da socialdemocracia. 
Vejamos alguns fragmentos de seus discursos de Lula durante as greves do ABC paulista em 1979 retirado do Filme ABC da Greve de Leon Hirszman:

Agora, é um pedido que eu faço: não saiam em passeata! Saiam daqui direto para as suas casas. Estamos entendidos?

(...) Estão dizendo que nós, trabalhadores, somos radicais; que há da nossa parte a insensibilidade; e que nós não queremos negociar. Em primeiro lugar: nós queremos negociar.

E eu acho, e aí é um voto de confiança que eu peço para vocês, para não dizer que nós somos radicais, nós vamos aceitar o pedido do governo, nós vamos voltar a trabalhar. (ABC DA GREVE, 1990).

Em 1989 o ministério do trabalho pôs fim à ditadura que exercia sobre os sindicatos, principalmente sobre a proibição dos funcionários públicos de fazerem greves e do estatuto padronizado dos sindicatos, mas continuou o corporativismo, pois perdurou o monopólio de representação e o Registro Sindical junto ao Ministério do Trabalho.

No Brasil na época do governo Collor (1990-1992), iniciaram-se os processos de privatizações, abrindo as portas do país para as importações e reduzindo cada vez mais as políticas sociais para garantir o pagamento da enorme dívida externa e interna do Brasil. Esta política foi acentuada nos mandatos de Fernando Henrique Cardoso (1994-2002), e seguida por Lula (2002-2010) e Dilma (2010-2014), com cortes de direitos dos trabalhadores e elevando-se o índice de desemprego. Boa parte dos sindicatos, dirigidos por Centrais Sindicais e sindicalistas vinculados aos governos mantêm uma posição de passividade frente ao ataque aos direitos, engessando as lutas de diversas categorias, como a dos trabalhadores em educação, sujeitos de nossa pesquisa, como veremos a seguir.

\section{AMPLA JORNADA, PRECARIZAÇÃO DO TRABALHO E DESVALORIZAÇÃO DOS TRABALHADORES EM EDUCAÇÃO NO ESTADO DE RONDÔNIA.}

O Sindicato dos Trabalhadores em Educação do Estado de Rondônia- SINTERO foi fundado nos dias 25 e 26 de fevereiro de 1989 no Salão Paroquial da Igreja Matriz de Ouro Preto do Oeste em um Congresso Intermunicipal onde aprovaram o estatuto e elegeram a primeira diretoria da entidade. É filiado à Central Única dos TrabalhadoresCUT, desde sua fundação. O primeiro presidente foi o professor Roberto Sobrinho, que permaneceu no cargo até 1993, quando deixou o sindicato para assumir a Secretaria Municipal de Educação de Porto Velho, sendo substituído pelo professor Nereu Klosinski. O primeiro se tornou prefeito de Porto Velho pelo Partido dos Trabalhadores-PT, por dois mandatos e foi cassado, acusado de corrupção e o segundo foi deputado estadual pela mesma sigla, também envolvido em casos de corrupção na Assembleia Legislativa de Rondônia. Outros membros da direção do SINTERO foram eleitos como a Senadora Fátima Cleide e diversos deputados e vereadores.

Já o Sindicato dos Servidores da Zona da Mata - SINSEZMAT foi formado no ano de 2004 a partir de um sindicato dos servidores municipais que já existia em Rolim de Moura. A partir daí, ampliou a sua base territorial para os municípios da Zona da Mata, onde representa todos os trabalhadores dos municípios desta microrregião, tendo atualmente cerca de 3.600 filiados. Atualmente é filiado à Força Sindical. 
Foram entrevistados dirigentes dos dois sindicatos e 300 trabalhadores em educação e nos municípios que compõem a Zona da Mata Rondoniense. A maioria dos professores e técnicos que entrevistamos é filiada ao SINTERO (Sindicato dos Trabalhadores em Educação do Estado de Rondônia), sendo um total de $56 \%$ dos entrevistados, por ser o sindicato que tem a maior base territorial (atua nas esferas federal, estadual e municipal). Quanto ao SINSEZMAT (Sindicato dos Servidores Públicos da Zona da Mata) somamos $30 \%$ dos entrevistados. O SINZESMAT atende aos municípios da Zona da Mata (uma das regiões mais populosas do Estado, o que o torna um importante sindicato), que são: Rolim de Moura, Santa Luzia d'oeste, Alto alegre dos Parecis, Parecis, Alta Floresta d'oeste, Nova Brasilândia D'oeste e Novo Horizonte D'oeste, representando todos os servidores públicos municipais. Já $13 \%$ dos nossos entrevistados não são sindicalizados. Muitos desses trabalhadores já foram filiados ao sindicato e, insatisfeitos, se desfiliaram. Apenas $1 \%$ é filiada a outros sindicatos.

Dentre os filiados do SINTERO E SINZESMAT (professores e técnicos) que entrevistamos, $83 \%$ afirmou que trabalha quarenta horas semanais e10\% tem uma carga horária de 60 horas. Quando perguntados se levavam trabalhos para casa, isto é, trabalhavam além da sua carga horária, 38\% afirmou que trabalhava em casa corrigindo provas, trabalhos, preparando aulas, etc. Já o restante afirmou que fazem essas atividades apenas nos horários de planejamento. Dentre os entrevistados, $24 \%$ fazem outras atividades de complementação salarial. No interior do espaço escolar, podemos observar que há um intenso comércio de produtos, realizado por professores ou técnicos, como, por exemplo, a venda de produtos de uso doméstico, cosméticos, perfumes, artesanatos, etc. "Se tivéssemos um salário digno talvez não precisássemos trabalhar em dois empregos e teríamos mais tempo para nos preparar e estudar para sermos mais atualizados", desabafou um dos entrevistados. Alguns entrevistados apontaram as funções que realizam como "bico" (atividades informais): músico; decorador de festas infantis, aniversários e casamentos; cabeleireiro; trabalhador em pecuária e atividades agrícolas; gari; artesão; elaborador de trabalhos acadêmicos; etc. Chamou-nos atenção algumas atividades laborais como a de professores que lecionam aulas particulares; professores "horistas" (substituição eventual de outros professores) ou que atuam como tutores em Educação à distância e em rede privada de ensino. A maior parte destas atividades não possui vínculo formal. A jornada de trabalho de muitos é extremamente desgastante, incluindo as horas de correções de trabalho dos alunos e planejamento. No caso das mulheres, a situação é ainda mais grave, pois além das atividades econômicas acumulam a jornada diária de trabalho doméstico.

Questionados sobre os principais fatores que incidem sobre o processo de opressão e desvalorização dos trabalhadores em Educação, alguns fatores aparecem como os principais: os baixos salários (82\%); a precarização do trabalho (43\%); desrespeito e desvalorização do trabalho docente pela sociedade (41\%), desrespeito dos alunos aos professores $(31 \%)$, carga horária elevada $(15 \%)$ e o autoritarismo dos gestores na implementação das políticas educacionais que resulta na intensificação do trabalho (12\%); Esses dados foram obtidos com um questionário onde marcaram em ordem de prioridade os fatores que consideravam mais relevantes em relação ao processo de opressão e desvalorização de seu trabalho, podendo marcar mais de uma opção numa lista de fatores elencados pelos pesquisadores.

A desvalorização salarial aparece como o principal, pois se trabalha muito e recebe pouco (o Estado de Rondônia oferece um dos mais baixos salários entre os Estados da Federação), o segundo aspecto apontado pelos entrevistados, que vem contribuindo para a 
desvalorização profissional são as condições de trabalho, pois o professor leciona em locais insalubres, sem ventilação, luz adequada, etc. Além de não ter recursos pedagógicos suficientes para realizar um trabalho de qualidade. Em relação às relações entre professoraluno e professor-sociedade, percebe-se que há uma relação conflituosa em que o professor e os demais trabalhadores em educação sente-se desprestigiados e desrespeitados em relação ao importante trabalho social que desenvolvem. O autoritarismo seria uma forma usual de desvalorização profissional. Em virtude do constante acúmulo de trabalho dos que tem dupla ou até tripla jornada, no caso dos professores, tornam-se meros reprodutores de atividades em sala de aula, sem tempo para pensar sobre as próprias condições de trabalho e as relações autoritárias que se colocam, ora de forma sutil ora de forma mais intensa, por meio de "pacotes" de orientações e atividades pedagógicas para serem aplicadas. Essas políticas, especialmente as de formação docente, a cada dia exercem mais controle ideológico sobre o trabalho do professor, impondo as chamadas pedagogias liberais pósmodernas por meio de módulos e avaliações institucionais.

Diante desse quadro, analisaremos o processo de luta e as ações dos sindicatos em defesa dos direitos desses trabalhadores.

\section{O CORPORATIVISMO SINDICAL E SUAS CONSEQUENNCIAS PARA A AS LUTAS DOS TRABALHADORES EM EDUCAÇÃO}

Em relação à luta por melhores condições de trabalho, 58\% dos entrevistados afirmou conhecer ações políticas dos sindicatos em que são filiados. Por outro lado, as entrevistas com os dirigentes sindicais dos dois sindicatos apontam para uma ação política em relação às condições de trabalho, mas apenas no campo jurídico (via denúncia ao Ministério Público ou com ação judicial). O SINSEZMAT informou haver feito um levantamento sobre algumas funções que necessitam de equipamentos de segurança e uma campanha com cartazes sobre a temática do Assédio Moral.

Sobre as ações políticas dos Sindicatos em relação às políticas/Programas Educacionais do Estado, 52\% dos que responderam aos questionários disseram não conhecer nada a respeito e que os seus sindicatos nunca fizeram nenhuma ação política sobre o conjunto das políticas educacionais que seguem os ditames do MEC e do Banco Mundial. Questionando os dirigentes sindicais, tivemos respostas evasivas, confusas e que alegam que as políticas educacionais "já são determinadas em nível nacional e que não podem ser questionadas". Os sindicatos agem de forma burocrática, seguindo os limites impostos pela legislação e reproduzindo uma visão derrotista à base.

Existem inúmeras formas de autoritarismo que atingem os trabalhadores em Educação, quer seja pela chefia imediata, pelas instâncias superiores da burocracia estatal ou por colegas de trabalho. Dentre os entrevistados, $71 \%$ afirmou que não conhecem nenhuma ação direta e muito menos denúncia dos sindicatos contra esses tipos de prática, com exceção, dos cartazes informando sobre a prática de assédio moral, feitos pelo SINZESMAT. Na maioria dos casos, o sindicato não faz denúncia pública contra o autoritarismo e o assédio moral nas escolas. $\mathrm{O}$ desconhecimento da categoria pode ser interpretado aqui não apenas como uma desinformação sobre a atuação do seu sindicato, mas por que não há em termos concretos uma preocupação real dos sindicatos e uma ação enérgica em denunciar e combater a prática do coronelismo.

Nossa pesquisa indicou que a educação em Rondônia é marcada pelos efeitos do coronelismo. Quando a educação é imposta, configura-se o que se convencionou chamar, na América Latina, de gamonalismo ou caciquismo, e que no Brasil denominamos 
coronelismo. Para compreendermos o fenômeno do coronelismo devemos relacioná-lo à semifeudalidade e às relações políticas estabelecidas no âmbito do poder local. "Ganhou força nos primeiros anos da República e se reforça ainda hoje, no conjunto de ações políticas em caráter local, regional ou federal, por meio da dominação econômica e social, especialmente no exercício do poder político" (SOUZA, 2014, p. 232). Conforme Souza (2014), o coronelismo não pertence ao passado. Está vigorosamente presente nas relações que se estabelecem no campo sob novas formas. Para Mariátegui, "o fator central do fenômeno é a hegemonia da grande propriedade semifeudal na política e no mecanismo de Estado" (MARIÁTEGUI, 2008, p. 54 e 55).

Em Rondônia o sistema político é fortemente vinculado às relações de dominação hegemônicas exercidas pelos latifundiários, diretamente ou indiretamente (por profissionais liberais, professores, etc., eleitos com seu apoio) (SOUZA, 2014, p.234) Mariátegui afirmou que onde vigora o coronelismo "a lei escrita é impotente":

O juiz, o subprefeito, o comissário, o professor, o coletor, estão todos enfeudados à grande propriedade. A lei não pode prevalecer contra os gamôneles. $\mathrm{O}$ funcionário que se empenhasse em impô-la seria abandonado e sacrificado pelo poder central, junto ao qual são onipotentes as influências do gamonalismo que atuam diretamente ou por meio do parlamento, por uma ou outra via, com a mesma eficiência (MARIÁTEGUI, 2008, p. 55).

Conforme Souza (2014, P. 235), “o coronelismo espalha seus tentáculos por todos os espaços da administração pública, em todos os níveis. O coronelismo ou gamonalismo não designa apenas uma categoria social e econômica dos latifundiários". Para Mariátegui, "o gamonalismo não está representado somente pelos gamonales propriamente ditos. Compreende uma grande hierarquia de funcionários, intermediários, agentes, parasitas, etc." (MARIÁTEGUI, 2008, p. 54).

Segundo Souza (2014, p. 235), "as ordens de implantação e todos os processos organizativos das políticas são definidos hierarquicamente, do escritório do Banco Mundial até a mais humilde secretaria de educação municipal, onde se efetivam de fato" e os professores acabam caindo no "canto da sereia das novas pedagogias nomeadas com o prefixo "neo"' (SAVIANI, 2007, p. 447).

Percebe-se nas entrevistas que não há uma ação política dos sindicatos em relação às politicas educacionais, contra o processo de degradação e precarização do trabalho e as relações coronelícias dos agentes do Estado na implantação das políticas educacionais e no trabalho desses profissionais, que a cada dia perde sua autonomia. Ainda mais grave é a constatação que poucos têm consciência crítica em relação às politicas educacionais e seus impactos na sua vida profissional.

\section{SINTERO E SINSEZMAT: UM AMÁLGAMA DE CONTRADIÇÕES}

O SINSEZMAT e o SINTERO possui uma característica que nos chamou muito atenção durante a pesquisa: a difusão da religiosidade. A religião está presente em vários processos da organização. Nos últimos anos se faz oração ao iniciar assembleias. Na sede do SINSEZMAT encontramos um banner "declarando" que o "o SINSEZMAT pertence a Jesus Cristo" seguido de vários itens de aclamação de fé e exorcismo. Essas práticas demonstram a intensidade do idealismo desses sindicatos e seu distanciamento dos 
processos mais rigorosos da luta de classe. Mas, as contradições principais desses sindicatos residem nos processos de corporativismo.

Em relação ao atrelamento do sindicato a partidos políticos eleitorais, $40 \%$ disseram que em determinados momentos (nas campanhas eleitorais) os sindicatos são atrelados, tendo em vista que os próprios presidentes dos sindicatos são dirigentes de partidos. 26\% responderam que os sindicatos são atrelados aos partidos. Somando os que disseram que seu sindicato é atrelado com os que disseram ser ele atrelado em "determinados momentos" teremos 66\% dos entrevistados que confirmam esse nível de corporativismo. A dirigente do SINTERO, Regional da Zona da Mata, informou que a maioria dos dirigentes desse sindicato é filiada ao Partido dos Trabalhadores (PT) e ao Partido Comunista do Brasil (PC do B), mas que o fato de serem filiados não interfere na autonomia e nos posicionamentos do sindicato. O principal dirigente do SINSEZMAT é filiado ao PSD (Partido Social Democrata), mas também há dirigentes que são filiados ao PT e outros partidos. Em 2010 o SINTERO assinou um documento, juntamente com vários sindicatos do Estado em apoio às candidaturas de Dilma (PT) para Presidente da República e de Confúcio Moura (PMDB) para Governador do Estado. Muitos dirigentes sindicais do SINTERO já se candidataram a cargos eletivos usando o nome do Sindicato (CLAUDIR DO SINTERO, MANOEL DO SINTERO, etc.). O presidente do SINSEZMAT foi candidato a vereador.

Sobre este aspecto, muitos entrevistados consideram que o sindicato (dados globais) é distante da base (14\%). Outros $20 \%$ assinalaram que o sindicato é trampolim eleitoral e $14 \%$ que o sindicato é atrelado a governos e descomprometido com a categoria. Esse dado aponta que quase 50\% dos que responderam ao questionário não aprova a atuação seus dirigentes sindicais. Outros $24 \%$ afirmou que o sindicato faz lutas apenas corporativas e salariais, ou seja, apenas faz lutas economicistas.

\section{CORPORATIVISMO: A MÃO DO IMPERIALISMO NAS ORGANIZAÇÕES SINDICAIS EM PAÍSES DE CAPITALISMO BUROCRÁTICO}

O corporativismo é um conceito adotado pela Carta del Lavoro do Estado fascista italiano. Ela foi seguida no Brasil por Getúlio Vargas no Estado Novo e resultou na Constituição de 1937 e no Decreto-lei No 1.402 de 5.7.1939, que regulou a sindicalização brasileira. A criação de sindicato dependia do enquadramento feito pela Comissão de Enquadramento Sindical, da adoção de um estatuto padrão e da expedição da Carta Sindical pelo Ministério do Trabalho. Esse Ministério podia controlar e interferir na administração dos sindicatos e cassar suas diretorias e a autorização de funcionamento se o sindicato não seguisse rigidamente as orientações e diretrizes impostas pelo Estado apesar da Convenção n. 87 de 1948 da OIT dispor a sobre a liberdade de organização sindical. A estrutura sindical brasileira é um legado do fascismo italiano e do autoritarismo fascista de Getúlio Vargas. A essência da estrutura sindical brasileira está descrita na CLT e define seu vínculo com o Estado. No Art. 513, São deveres dos sindicatos: "d) colaborar com o Estado, como órgãos técnicos e consultivos, no estudo dos problemas que se relacionam com a respectiva categoria ou profissão liberal". No Art. 514 dispõe que: São deveres dos sindicatos: "e) colaborar com os poderes públicos no desenvolvimento da solidariedade social." Essa estrutura não serve ao proletariado, mas às classes dominantes, pois seu princípio básico é a colaboração de classes e consequentemente o corporativismo que se desenvolve por meio da unicidade sindical (o Estado reconhece um único sindicato de uma mesma categoria numa mesma base territorial) da investidura sindical, que é o poder dado ao sindicato pelo Estado para representar os trabalhadores e ainda, do imposto sindical que 
é um mecanismo de regulação que obriga o sindicato a realizar atividades assistencialistas. A Constituição Brasileira de 1988 prevê a não interferência do Poder Público nos sindicatos, entretanto na prática há uma série de limitações no cumprimento desse postulado, prevalecendo essa estrutura fascista.

Conforme Dimitrov (1953, p. 1), o fascismo não é um fenômeno local, temporal ou transitório, mas um sistema de dominação de classe da burguesia capitalista e da sua ditadura na época do imperialismo e da revolução social.

El fascismo es la última fase de la dominación de clase de la burguesía. Todos los países burgueses pasan uno tras otro, tarde o temprano, al fascismo - por medio de golpes de Estado o de manera "pacífica"; de manera máa brutal o "más suave"- los métodos de transición pueden ser diversos y dependen de las particularidades, de las circunstancias, de la estructura social y de la correlación de las fuerzas de clase y políticas e nun país determinado. (DIMITROV, 1953, p, 2).

Após as ditaduras fascistas de Vargas e a civil-militar não se compreendeu que o fenômeno do fascismo na época do imperialismo não é transitório e apostou-se mais uma vez na ilusão da democracia eleitoral burguesa e não na luta revolucionária. Assim, a falta de uma orientação classista e ação do oportunismo de direita no seio do movimento sindical, abriram caminho para uma frente de sindicalistas anticomunistas, guerrilheiros arrependidos, trotskistas, intelectuais da pequena-burguesia liberal e outros tantos renegados do marxismo e traidores financiados pelo imperialismo nas direções dos mais importantes sindicatos do país. Esse processo desenvolveu-se na organização do Partido dos Trabalhadores e de centrais sindicais como a Central Única dos Trabalhadores - CUT, que mesmo tendo dirigido muitas lutas nos primeiros anos de sua criação, a fim de ganhar as massas, não avançou na luta de classe e desde o inicio alimentou o corporativismo.

Um dos aspectos do corporativismo sindical é o atrelamento aos partidos eleitorais. Desde seu nascimento em 1983, a CUT está articulada ao projeto do Partido dos Trabalhadores (PT), adotando o discurso do "novo sindicalismo", mas sua prática, ao longo do tempo, se reproduziu como colaboracionismo de classes. A Força Sindical foi fundada em 1991, com apoio do governo Collor, do patronato e do oligopólio nacional dos meios de comunicação, sob o lema pelego do "sindicalismo de resultados".

Essas centrais Sindicais, as quais os sindicatos que estudamos estão vinculados, praticam um sindicalismo de Estado e tem vínculos umbilicais com o imperialismo. Sindicalistas ocuparam e ocupam cargos de direção do Estado, como a presidência da República, Ministérios outros cargos em todas as esferas da administração público ${ }^{6}$ defendendo as reformas ditadas pelo imperialismo, como a reforma fiscal, reforma da previdência, etc. que retiram direitos trabalhistas conquistados às duras penas pelos trabalhadores.

Conforme análise do editorial do Jornal A Nova Democracia, Ano I, N 11, de julho de 2003, essas centrais sindicais se uniram às teses e das ações articuladas nas representações do sindicalismo amarelo internacional: a Ciosl e a AFL-CIO ${ }^{7}$. Desde a sua criação em 1983, a CUT se vincula ao imperialismo ianque, estabelecendo relações muito próximas com Stanley Gacek (que acompanhou Lula em toda sua trajetória, desde as viagens aos EUA ao Palácio do Planalto), dirigente da AFL-CIO, organização que atua junto com a CIA em todos os países semicoloniais. A filiação da CUT à CIOSL foi 
aprovada no IV Congresso da CUT. Essa aprovação foi articulada pelo grupo hegemônico na CUT que também dirigia o PT.

Em 2006, a Confederação Internacional das Organizações Sindicais Livres Ciosl, e a Confederação Mundial do Trabalho - CMT, se uniram e criaram a Confederação Sindical Internacional- CSI que assumiu em seu estatuto o lema do maior sindicato anticomunista dos USA, o AFL-CIO: Paz entre as classes. Esse lema remete ao engodo do "imperialismo humanista". A CUT, Força Sindical e CGT aderiram a essa "nova" Confederação, dirigida pelos organismos do imperialismo na sua luta contra o avanço do socialismo ${ }^{8}$. A CMT nasceu em 1920 sob o nome de CISC (Confederação Internacional dos Sindicatos Cristãos), sendo a mais antiga internacional sindical existente. A CMT tem vinculação direta com o Vaticano e congrega os sindicatos amarelos ou confessionais. A expressão "sindicatos amarelos" provém do uso da bandeira do vaticano de cor amarela. Essa confederação sempre foi dirigida por orientações fascistas.

O braço CSI na América Latina é conhecido como Organização Regional Interamericana dos Trabalhadores ORIT que atua no processo de cooptação dos sindicatos.

As centrais sindicais brasileiras historicamente foram cooptadas e controladas pelo imperialismo europeu e norte-americano. Esse controle é exercido em parceria com outros órgãos do imperialismo na atualidade como o Fundo Monetário Internacional e o Banco Mundial. Essa condição nos ajuda a compreender o processo de corporativismo sindical e especificamente nos sindicatos dos trabalhadores em educação.

\section{IMPERIALISMO E O SINDICALISMO DOCENTE}

O sindicalismo docente emerge de dois segmentos de trabalhadores assalariados: do magistério público e do magistério privado. A legislação sindical vedou a organização sindical os funcionários públicos até a Constituição de 1988. Antes disso havia organizações combativas de trabalhadores em educação em entidades que juridicamente não eram sindicais, mas que tinham um caráter de organização sindical. A partir de 1980 com a eclosão do "Novo Sindicalismo" o movimento dos trabalhadores em educação, especialmente o movimento docente ganha força e se organiza em todo o território nacional em torno de direitos trabalhistas, da democratização da escola pública e da escola (MIRANDA, 2011, p. 344).

Os sindicatos dos trabalhadores em educação na atualidade estão mais susceptíveis ao controle dos órgãos multilaterais do imperialismo, já que participam diretamente dos processos de decisão e gestão da educação por meio de conselhos em todas as esferas da administração pública ${ }^{6}$. Essa participação não foi uma conquista, mas uma orientação do Banco Mundial aos Estados de capitalismo burocrático com o objetivo de cooptá-los para que colaborem com o governo na implementação das reformas: "La eficacia de la colaboración entre el gobierno y los sindicatos de maestros para lograr la reforma ha quedado demostrada em varios países" (BANCO MUNDIAL, 1996, p. 157 ). Se decidem junto com aparelho do Estado, como se opor a ele na implementação das políticas educacionais? O processo de cooptação dos sindicatos de professores tem sido orientado passo a passo nos documentos do Banco Mundial, como exemplo, o seguinte:

Debido a que el financiamiento y la administración de la educación están normalmente a cargo del gobierno central, los sindicatos de maestros son importantes protagonistas del ámbito político nacional. Por ejemplo, en América Latina, Europa oriental y algunos países de Asia, han llegado a 
estabelecer sus proprios partidos políticos o han formado alianzas con partidos que representan a los movimentos sindicales. Cuando los gobiernos no llegan a um acuerdo com los poderosos sindicatos centrales com respecto a las condiciones de empleo de los maestros, la acción colectiva puede perturbar la educación y a veces culminar en una parálisis política, como ha ocorrido em Bolivia, el Perú y otros países em los últimos años. (BANCO MUNDIAL, 1996, p. 173)

Percebe-se que o Banco reconhece a importância das alianças do Estado burguês com os partidos que representam os movimentos sindicais ou orientação no sentido de criação de partidos políticos no seio do sindicalismo. No Brasil isso se solidificou no desenvolvimento e atuação do PC do B, PT, PCB, PCO, dentre outras siglas, organizadas no seio do oportunismo eleitoral. Sendo assim, nada mais natural que o eleitoralismo e o envolvimento dos dirigentes sindicais com partidos e outras instituições do Estado.

Para compreender a realidade do sindicalismo brasileiro é preciso antes de tudo compreender que durante muitas décadas o imperialismo e as classes dominantes utilizando-se dos prestimosos serviços dos oportunistas e revisionistas que atuam no movimento sindical e de uma intelectualidade liberal que tergiversa ou oculta a realidade econômica, buscando confundir os trabalhadores e seus sindicatos para que não lutem contra a opressão e se o fazem, o fazem de uma maneira subjetiva, errada, nos objetivos e nos métodos (CAMPOS, 2011, p.4). A maioria absoluta dos sindicatos no Brasil, a exemplos dos sindicatos analisados nessa pesquisa, não tem qualquer visão classista e combativa, de luta contra todas as formas de exploração dos trabalhadores e contra o modo de produção capitalista. Por isso, em muitos Estados os trabalhadores vêm travando lutas e organizando lutas combativas e classistas a revelia da direção de seus sindicatos, como foi o caso da greve dos Garis no Rio de Janeiro em 2013, dos trabalhadores em educação no Paraná e Goiás em 2015, com enfrentamento a todas as formas de repressão.

\section{CONSIDERAÇÕES FINAIS}

O que observamos é a ausência de um programa contra o imperialismo e o capitalismo de uma forma mais articulada. Na maioria dos casos, os sindicatos não vinculam suas lutas - a maioria delas corporativas salariais - com as necessidades da população que na maioria das vezes é afetada pelas mesmas políticas, como é o caso dos sindicatos analisados. A desvalorização profissional ocorre em vários aspectos e há descrédito em relação ao sindicato pela maioria dos entrevistados, apontado como atrelado ao Estado e aos partidos políticos eleitorais, como um trampolim eleitoral. Sindicatos como o SINTERO e SINZESMAT não contribuem para o avanço da luta de classes na sociedade atual, devido ao elevado nível de corporativismo e se restringem às lutas corporativistas e economicistas. Para Marx, os trabalhadores não deveriam fechar-se apenas no resultado final das lutas diárias. Para ele, o que cotidianamente ocorre é que se luta "contra os efeitos, mas não contra as causas desses efeitos". Ou seja, na maioria das vezes "aplica paliativos, mas não cura a enfermidade" (MARX, 1983, p. 77). Os sindicatos, ao mesmo tempo em que travam lutas contra os efeitos do sistema existente, deveriam lutar também para mudá-lo, utilizando-se de sua organização para alavancar a emancipação do proletariado.

Compreendemos que, com o desenvolvimento do imperialismo, a aristocracia operária ganhou papel de destaque no processo de manutenção da estrutura capitalista, direcionando as organizações sindicais e suas bases para lutas meramente economicistas e 
eleitoreiras, por isso, faz-se necessário destruir essa estrutura sindical fascista e construir sindicatos classistas que lutem contra as reformas que a cada dia corroem direitos e ampliam a exploração sobre os trabalhadores da cidade e do campo e, sobretudo, que avancem na luta política e no desenvolvimento da luta de classes.

Lênin em $O$ imperialismo: fase superior do capitalismo apontou que a obtenção de elevados lucros, possibilitou aos monopólios subornarem certos setores operários, atraindo-os para o lado da burguesia. A estes setores Lênin chamou de "aristocracia operária" ou simplesmente "oportunismo", que atado diretamente ao imperialismo utiliza de suas posições no seio do movimento operário para desorganizá-lo. O oportunismo é um fenômeno derivado e inevitável do imperialismo. Portanto, "a luta contra o imperialismo, quando não se liga indissoluvelmente à luta contra o oportunismo, se reduz a uma fraseologia oca e mentirosa" (LÊNIN, 1979, p. 125).

A luta dos comunistas revolucionários é o de combater o oportunismo no seio do movimento sindical, ligando às lutas econômicas às lutas gerais de destruição da ordem capitalista vigente e apresentando a alternativa revolucionária. Em países semicoloniais e semifeudais como o Brasil, onde a revolução burguesa foi inconclusa, faz-se necessária uma revolução democrático-burguesa de novo tipo, enquanto revolução de Nova Democracia ininterrupta ao Socialismo.

\section{REFERÊNCIAS BIBLIOGRÁFICAS:}

ABC DA GREVE. Direção: Leon Hirszman. Distribuição e Produção: Taba Filmes e Cinemateca Brasileira. Documentário, Brasil, 1990, Duração: 75 min. Formato: 16mm.

BANCO MUNDIAL. Prioridades y estratégias para la educación. Examen del Banco Mundial. Washington, DC, EEUU, 1996.

BATALHA, C. H. M. Sociedades de trabalhadores no Rio de Janeiro do século XIX: algumas reflexões em torno da formação da classe operária. In: Cadernos AEL. Vol. 6, No 10/11 (1999). Sociedades Operárias e Mutualismo. Disponível em:

http://www.ael.ifch.unicamp.br/publicacoes_ael/index.php/cadernos_ael/article/view/91/95

CAMPOS, M. El Capitalismo Burocrático em Ecuador. Disponível em http://pt.scribd.com/doc/72141849/Miguel-Campos-El-capitalismo-burocratico-en-el Ecuador. Acesso em 19 de Fevereiro de 2014.

DIMITROV, J. Acerca de las medidas de lucha contra el fascismo y los sindicatos amarillos. Obras Completas, Editorial del PCB, 1953.

FERREIRA, M. N. A Imprensa Operária no Brasil (1880-1920). Petrópolis: Vozes, 1978.

JORNAL A NOVA DEMOCRACIA. O Congresso Nacional da CUT: O fim de um ciclo de traição do sindicalismo amarelo. Ano I, $\mathrm{n}^{\circ} 11$, julho de 2003. Disponível em: http://www.anovademocracia.com.br/no-11/1109-8o-congresso-nacional-da-cut-o-fim-deum-ciclo-de-traicao-do-sindicalismo-amarelo. Acesso em 15 de maio de 2015.

- A reciclagem do sindicalismo colaboracionistaAno VI. $\mathrm{n}^{\circ}$ 37, outubro de 2007

Disponível em: http://www.anovademocracia.com.br/no-37/136-a-reciclagem-do

sindicalismo-colaboracionista. Acesso em 15 de maio de 2015. 
GUZMÁN, A. La problemática nacional: discurso pronunciado no Sindicato de Docentes de Huamanga, Lima, Peru, 1974.

LÊNIN, V. I. O imperialismo: fase superior do capitalismo. Tradução de Olinto Beckerman. 1. Ed. São Paulo: Global, 1979.

LEÃO XIII, Papa. Rerum Novarum - sobre a condição dos operários (1891).

Disponível em http://www.montfort.org.br/rerum-novarum-2/. Acesso em 20 de maio de 2015

MAO TSETUNG. Notas del presidente Mao sobre capitalismo burocrático.2.ed. Lima: Ediciones Alborada, 2008.

MARIÁTEGUI. J. C. Sete ensaios de interpretação da realidade peruana. São Paulo: Expressão Popular, 2008.

MARX, K. Salário, preço e lucro. In: MARX, K; F. ENGELS. Obras escolhidas. Lisboa: Edições Avante / Moscou: Editorial Progresso, 1983, p. 319-321, t. 2

MARX. K. \& ENGELS, F. A ideologia alemã. Tradução de Luiz Cláudio de Castro e Costa. São Paulo: Martins Fontes, 1989.

Manifesto do Partido Comunista. São Paulo: Cortez, 1998.

MARTÍN MARTÍN, V. O. El papel del campesinato en la transformación del mundo actual. Valencia: Baladre, 2007.

MATTOS, M, B. Trabalhadores e sindicatos no Brasil. São Paulo: Expressão Popular, 2009.

MIRANDA. K.A. As lutas dos Trabalhadores da Educação: do novo sindicalismo à ruptura com a CUT. Tese de Doutorado, Programa de Pós-Graduação em História, Universidade Federal Fluminense, Rio de Janeiro, 2011.

PENTEADO, J. Belenzinho 1910. São Paulo: Martins, 1962.

SANTIAGO, A. M. O. V. O Banco Mundial e a gestão da educação brasileira: grandes desafios. Revista de desenvolvimento social. Montes Claros. Disponível em:

http://www.rds.unimontes.br/index.php/desenv_social/article/viewFile/93/80. Acesso em: 10 de jun. 2014.

SAVIANI, D. História das ideias pedagógicas no Brasil. Campinas: Autores Associados, 2007.

SOUZA, M. M. Imperialismo e educação do campo. Araraquara/SP: Cultura Acadêmica, 2014. Coleção Temas em Educação Escolar, n.19. 
1. Doutora em Educação Escolar - UNESP - Campus de Araraquara, Professora Adjunta da Universidade Federal de Rondônia.

2. Bolsista do Programa Institucional de Iniciação Científica PIBIC - graduanda em Pedagogia, Universidade Federal de Rondônia.

3. Mestre em Geografia e professor de História do Instituto Federal de Educação e Tecnologia de Rondônia IFRO - Campus de Vilhena/RO.

4. O texto integral desse decreto pode ser visto em: http://www2.camara.leg.br/legin/fed/decret/19001909/decreto-1641-7-janeiro-1907-582166-publicacaooriginal-104906-pl.html. Acesso em 25 de maio de 2015.

5. In: O PCB e sua atuação nos anos 50: Waldir José Rampinelli entrevista Jacob Gorender. Rev. Bras. Hist. [online]. 2003, vol.23, n.45, pp. 303-309. ISSN 1806-9347.

6. Em 2003, 66 destacados antigos dirigentes da CUT ocupam altos cargos na gerência do Estado. Um é o presidente da República, nove são ministros, três são secretários de Estado e outros cinquenta e três ocupam postos-chave nos ministérios e no Palácio do Planalto. Isso sem falar nos diversos líderes da CUT que ocupam cargos federais nos estados, no Itamarati, nas empresas estatais e até na direção de conselhos de entidades de caráter nitidamente patronal, como o SESI (Serviço Social da Indústria) — caso de Jair Meneguelli, primeiro presidente da CUT. Já no podre parlamento burguês (Congresso Nacional, assembleias legislativas dos estados, câmaras municipais de vereadores) e prefeituras pululam centenas e centenas de ex-sindicalistas, alçados a esses cargos pelo trampolim da CUT. (http://www.anovademocracia.com.br $)$

7. Ciosl (Confederação Interamericana das Organizações dos Sindicatos Livres) - Já em 1949 financiada pelo USA como uma dissidência da Federação Sindical Mundial (FSM). A Ciosl é junção da AFL (American Federation of Labor Unions), TUC (Trades Union Congress) e CIO (Congress of Industrial Organizations). Seu braço (secretariado) para a América Latina é a Orit (Organização Regional Interamericana de Trabalhadores), fundada em 1951, ligada ao Iadesil (Instituto Americano de Desenvolvimento do Sindicalismo Livre), que administra cursos contra-revolucionários de "liderança" sindical. A CUT, a Força Sindical, a CGT (Confederação Geral dos Trabalhadores), etc., foram filiadas à Ciosl. A FSM, criada em Paris no ano de 1945, no I Congresso Mundial dos Sindicatos, chegou a ser a mais combativa organização sindical do mundo e congregou cerca de 190 milhões de membros.AFL-CIO (American Federation of Labor - Congress of Industrial Organizations) - A AFL surge em 1955 e é a maior central sindical do USA, enquanto a CIO, outra central do mesmo país, é menos expressiva. Essa junção sindical jamais escondeu suas origens contrarrevolucionárias e seu papel

intervencionista. Por ser um instrumento do imperialismo no controle das lutas sindicais na América Latina, é também chamada ironicamente de "AFL- CIA". (http://www.anovademocracia.com.br/no-11/1109-8ocongresso-nacional-da-cut-o-fim-de-um-ciclo-de-traicao-do-sindicalismo-amarelo).

8. A CSI nasceu da Ciosl, que nasceu da AFL-CIO, que nasceu da AFL, que depois da Primeira Guerra Mundial tentou, sem sucesso, criar uma Federação Pan-Americana de Sindicatos para cooptar as organizações de trabalhadores das Américas do Norte, Central e do Sul.

Recebido: jun/2015 $\quad$ Aprovado: jul/2015 